INFORMATION

PLEASE 



\section{Mark Poster}

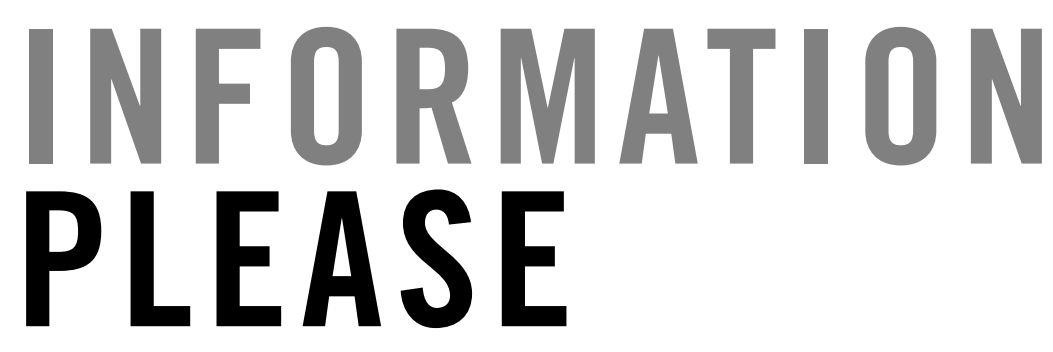

CULTURE AND

POLITICS IN THE AGE OF

DIGITAL MACHINES

Duke University Press

Durham and London 2006 
() 2006 Duke University Press

All rights reserved

Printed in the United States of America on acid-free paper @

Designed by Heather Hensley

Typeset in Quadraat and Linotype Trade Gothic by Tseng Information Systems, Inc.

Library of Congress Cataloging-in-Publication Data and republication

acknowledgments appear on the last printed pages of this book. 
FOR ZACHARY KAROL, IN MEMORIAM 
